\title{
Indoor Air Quality Assessment in Critical Care Department in One Hospital of The General Organization of Teaching Hospitals and Institutes in Cairo Mohamed Mostafa Abdelghaffar ${ }^{1}$, Sahar Abdelfattah ${ }^{2}$, Neveen Mahmoud ${ }^{3}$, Hoda Shoman ${ }^{3}$ \\ ${ }^{1}$ Department of Gastoenterology and Infectious Disease, Faculty of Medicine, Cairo University, Egypt ${ }^{2}$ Department of Infection Control Specialist in General Organization for Teaching Hospital and Institutes (GOTHI), Egypt, ${ }^{3}$ Department of Experimiental Zoology, Faculty of Science, Al-Azhar University, Egypt \\ *Corresponding Author: Sahar Abdelfattah Hassan, Phone No.: (+2) 01018020572, E-mail: Saherabdelfatah55@gmail.com
}

\begin{abstract}
Background: Among hospitals-related health risks, environmental factors play a key-role; this accounting for different rooms' specific use, patients' vulnerability and risk of overcrowding. For these reasons, air control in hospitals and in healthcare facilities in general deserves scientific attention.

Objective: Assessing of the quality of indoor air ventilation in critical care department hospitals and its effect on the incidence of hospital acquired infections in order to optimize the ventilation methods in hospitals.

Patients and methods: Our study was performed in Egypt by correlating the examined 70 air samples, from the Intensive Care Unit (ICU), Cardiac Care Unit (CCU) and Neonatal Intensive Care Unit (NICU) in one of the General Organization of Teaching Hospitals and Institute, for presence of bacterial and fungal contamination with the concomitant infection of 70 patients admitted in these units during the period from November 2019 to January 2020.

Results: We had $59(84.2 \%)$ positive air samples in comparison to $21(30 \%)$ positive endotracheal tube (ETT) fluid culture and $19(27.1 \%)$ positive blood cultures in the completely selected air sampling areas and in the selected patients during the included sampling period. This suggested a strong relation between the contamination between the indoor airs either by bacterial or fungal organisms, and between the concomitant presence of the same organism in the ETT fluid samples and to lesser extent in the blood cultures.

Conclusion: This study has fortified the hypothesis that achieving an optimal level of indoor air quality is related to applying the infection control rules, application of approved air filters and strict adherence to hand hygiene.

Keywords: Air Quality, Critical Care Unit.
\end{abstract}

\section{INTRODUCTION}

The indoor air quality is an issue of growing scientific interest both because the risks due to exposure to air pollution in indoor environments became more evident and stated by WHO of improving public health and quality of life ${ }^{(\mathbf{1})}$. Indoor pollution levels are affected by air quality, materials, room ventilation, type of furniture, equipment and products, occupants' habits (including passive smoking), and overall building management, according to the European Union and specifically the European Environmental Agency (EEA) in the reports of Environment and Human Health and Environmental Signals $2013^{(2)}$.

The air quality criteria in healthcare facilities vary by health function and, in certain cases, even by room in relation to its utilisation. Some areas, such as operating rooms, intensive care units, and isolation rooms, require high-efficiency filtration to protect patients, staff, and visitors, while others require the removal of gaseous contaminants, chemical contaminants, and odours to create a safer and more pleasant working environment ${ }^{(2)}$.

Regarding biological risks, they are related to the presence of microorganisms (fungi, bacteria, viruses, parasites, protozoa, etc.), dust mites, animaland plant-derived allergens found in the air, in the dust, in construction materials and furniture, in engineering plants' water, and in air conditioning. It is mainly influenced by physical factors, such as humidity and temperature. Individuals potentially exposed to this risk including all age groups, in particular the most vulnerable ones, such as children and elderly. The biological risk in healthcare facilities can be controlled and reduced through interventions of both structural and engineering plans' actions and in respect of basic hygienic and behavioral knowledge by facility managers, workers, and users ${ }^{(3)}$. When this risk is not well managed and monitored, infectious risks can arise, affecting several categories of people involved in the hospital, which are contaminated directly, through the respiration of biological agents (bacteria, viruses, fungi, endotoxins, spores, etc.) and their physique ${ }^{(4,5)}$.

In this descriptive study, we aimed at assessing the quality of indoor air ventilation in critical care department hospitals and its effect on the incidence of hospital acquired infections in order to optimize the ventilation methods in hospitals.

\section{MATERIALS AND METHODS}

Type of Study: A Descriptive Study.

Study Setting: Our study was performed in Egypt by correlating the examined 70 samples of air, from the ICU, CCU and NICU in one of the General Organization of Teaching Hospitals and Institute, for presence of bacterial and fungal contamination with the concomitant infection of 70 patients admitted in these units.

Study Period: from November 2019 to January 2020. 
Inclusion Criteria: Patients admitted into CCU, ICU and NICU in the study period.

Exclusion criteria: Excluding other departments in the hospital.

Sampling Method: according to the inclusion and the exclusion criteria.

Sample Size: 70 patients and 70-air sample.

\section{Ethical Considerations:}

Patients freely gave fully informed consent to participate. These informed consents in this retrospective study were verbal consents. Participant's confidentiality and data security were guaranteed. Participants should be able to withdraw from the research process at any time, they also should be able to withdraw their data if it is identifiable for them and should be told when this will be no longer be possible. Explaining of any expected benefits or any possible risk of the research to participants.

\section{Study Tools:}

1- An air sampler device used to obtain air samples from front of beds, sampling tables, nursing counter, isolation rooms, drugs preparation room, air conditioner outlet, neonates incubator and ventilations devices tubes in the ICU, CCU and NICU.
2- Vitek 2 compact CT in Les pennes-mirabeau, France device for identification of microorganisms.

\section{Statistical Analysis}

Data were collected, revised, coded and entered to the Statistical Package for Social Science (IBM SPSS) version 23. The quantitative data were presented as median and inter-quartile range (IQR) when data found non-parametric. Also qualitative variables were presented as number and percentages. The comparison between groups with qualitative data was done by using Chi-square test. The comparison between more than two groups with quantitative data and non-parametric distribution was done by using Kruskall Wallis test. The confidence interval was set to $95 \%$ and the margin of error accepted was set to $5 \%$. So, the p-value was considered significant as the following: $\mathrm{P}>0.05$ : Nonsignificant, $\mathrm{P} \leq 0.05$ : Significant, $\mathrm{P}<0.01$ : Highly significant.

\section{RESULTS}

We performed 70 air samples (42.8\% from ICU, $35.7 \%$ from NICU and $21.4 \%$ from CCU). $29(41.4 \%)$ of the air samples were obtained from front of the bed.

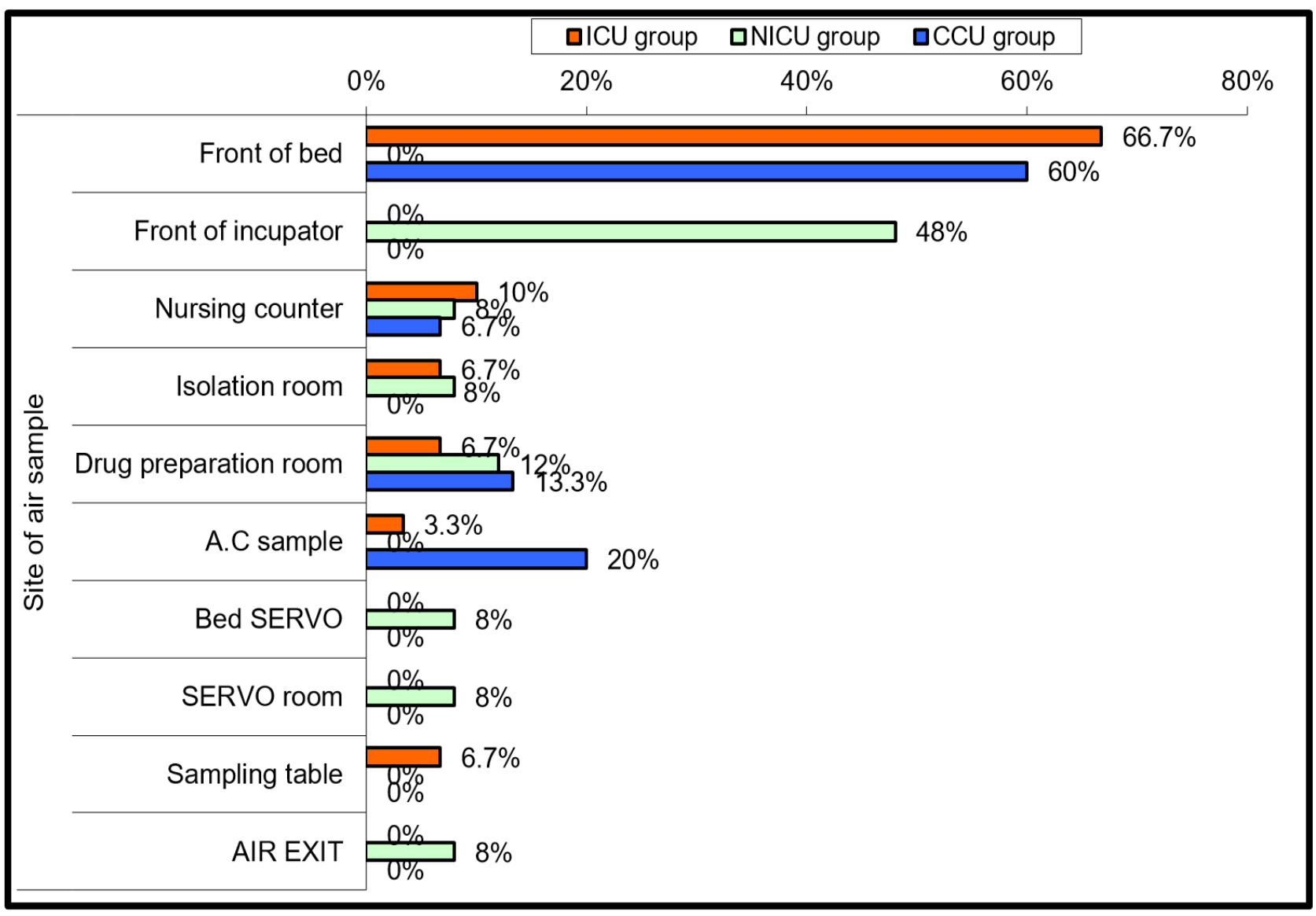

Fig. (1): Distribution of air sampling sitesb

The time of screening was insignificant in affecting the results between ICU, NICU and CCU ( $p$ value $=0.954$ ). Furthermore, there was no significance regarding the site of air samples between the 3 groups except in samples obtained from the front of the bed in ICU group $(66.7 \%)$ with p value $=0$ and those obtained from front of the incubator $(48 \%)$ with a $\mathrm{p}$ value $=0($ Figure $1 \&$ table 1$)$. 
Table (1): Timing, sites of air sampling, duration of stay statistics among the 3 groups ICU, NICU and CCU

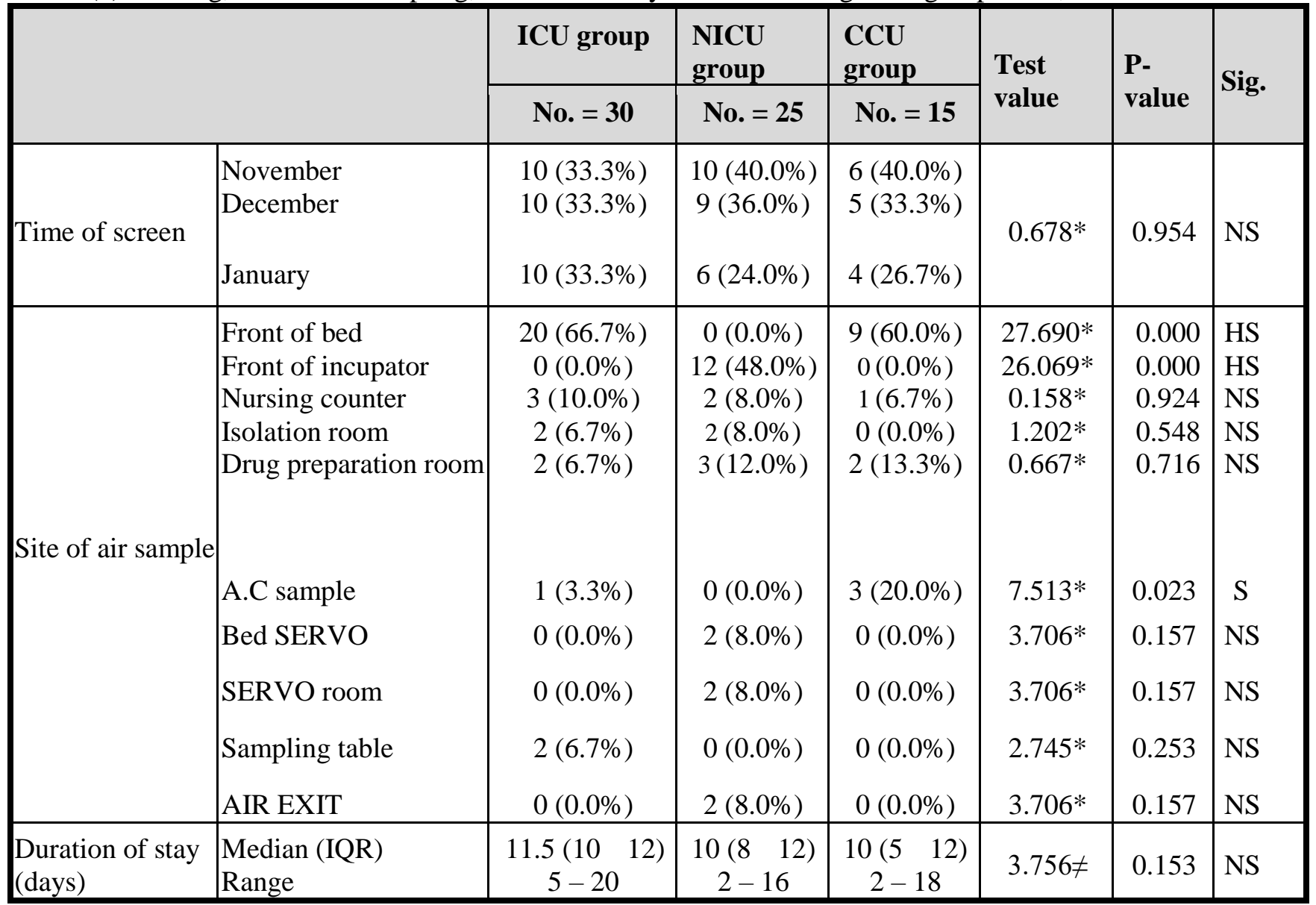

70-blood culture and 70 ETT samples were obtained from 70 patients admitted in the selected units during the study period with $42.8 \%$ from ICU, 35.7\% from NICU and 21.4\% from CCU. In ETT samples, 24 samples (34.2\%) showed no growth of any organism while 46 samples (65.7\%) showed presence of bacterial or fungal infection distributed as shown in figure (2) and table (2).

Table (2): Statistical analysis of bacterial and fungal contamination of the ETT samples among 3 groups of ICU, NICU and $\mathrm{CCU}$

\begin{tabular}{|c|c|c|c|c|l|l|}
\hline \multirow{2}{*}{ ETT } & ICU group & NICU group & CCU group & \multirow{2}{*}{ Test value } & $\begin{array}{l}\text { P- } \\
\text { value }\end{array}$ & Sig. \\
\cline { 2 - 6 } & No. $=30$ & No. $=25$ & No. $=15$ & & $\mathbf{0}$ \\
\hline N.g & $12(40.0 \%)$ & $7(28.0 \%)$ & $5(33.3 \%)$ & $0.879 *$ & 0.644 & NS \\
\hline Candida & $2(6.7 \%)$ & $2(8.0 \%)$ & $0(0.0 \%)$ & $1.202 *$ & 0.548 & NS \\
\hline Staph haemolyticus & $1(3.3 \%)$ & $1(4.0 \%)$ & $1(6.7 \%)$ & $0.279 *$ & 0.870 & NS \\
\hline Pseudomons & $1(3.3 \%)$ & $2(8.0 \%)$ & $1(6.7 \%)$ & $0.583 *$ & 0.747 & NS \\
\hline Strepto penumonia & $0(0.0 \%)$ & $3(12.0 \%)$ & $1(6.7 \%)$ & $3.67)^{*}$ & 0.159 & NS \\
\hline Koci -rhizophila & $2(6.7 \%)$ & $0(0.0 \%)$ & $1(6.7 \%)$ & $1.741 *$ & 0.419 & NS \\
\hline Citro bacter & $1(3.3 \%)$ & $0(0.0 \%)$ & $1(6.7 \%)$ & $1.544 *$ & 0.462 & NS \\
\hline Staph scuri & $1(3.3 \%)$ & $0(0.0 \%)$ & $0(0.0 \%)$ & $1.353 *$ & 0.508 & NS \\
\hline
\end{tabular}

P-value > 0.05: Non significant; P-value < 0.05: Significant; P-value < 0.01: Highly significant*: Chi-square test. 


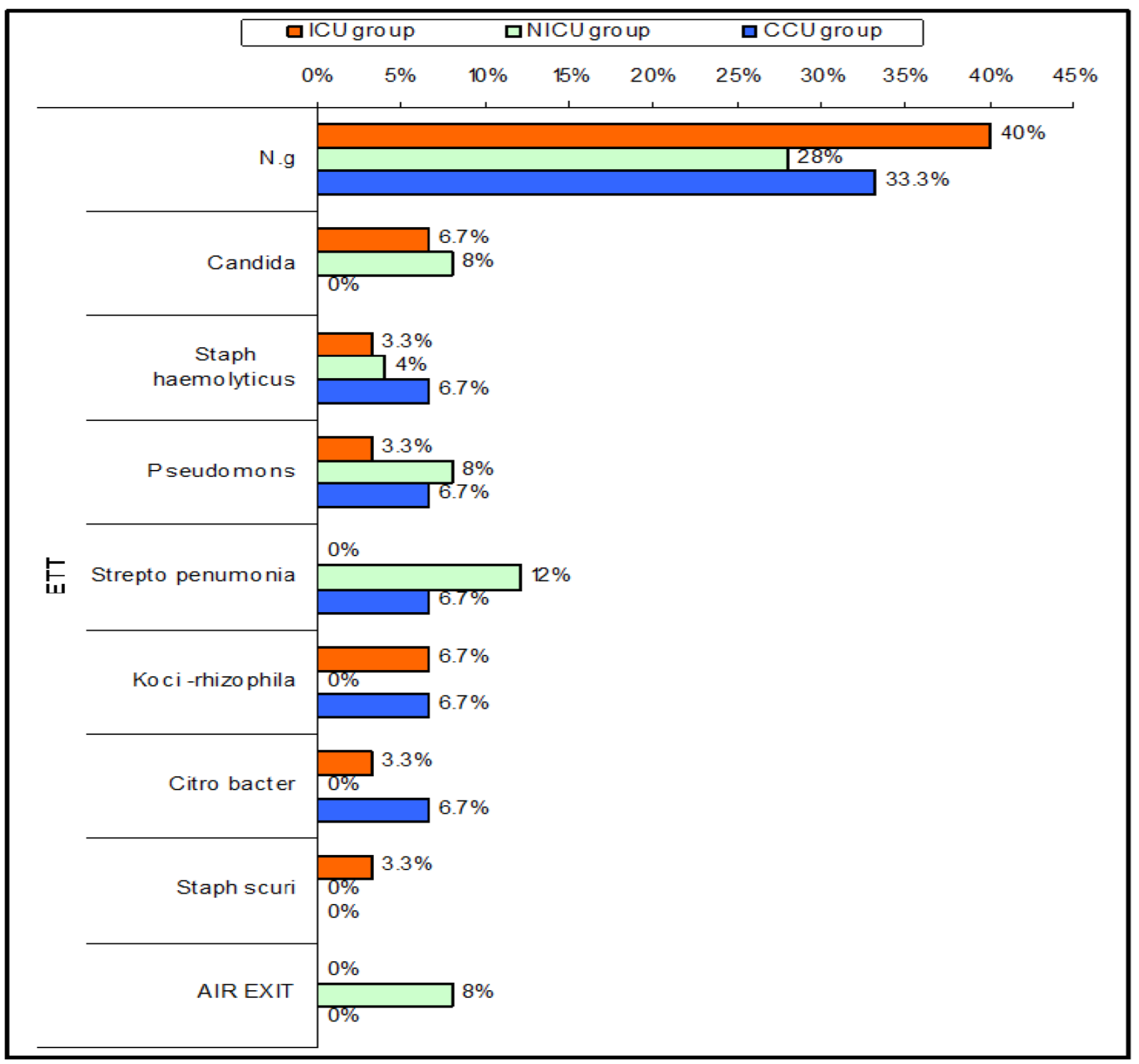

Fig. (2): Distributional of bacterial and fungal contamination of the ETT samples among 3 groups of ICU, NICU and $\mathrm{CCU}$

In blood culture samples, 58 samples (82.8\%) showed no growth of any organism while 12 sample (17.2\%) showed presence of different organisms distributed as shown in figure (3) and table (3).

Table (3): Statistical analysis of bacterial and fungal presence in the blood cultures samples among 3 groups of ICU, NICU and CCU

\begin{tabular}{|c|l|c|c|c|c|c|c|}
\hline \multicolumn{2}{|c|}{} & ICU group & NICU group & CCU group & \multirow{2}{*}{ Test value } & \multirow{2}{*}{ P-value } & Sig. \\
\cline { 3 - 6 } \multicolumn{2}{|c|}{} & No. = 30 & No. = 25 & No. = 15 & & & \\
\hline & N.g & $24(80 \%)$ & $21(84.0 \%)$ & $13(86.6 \%)$ & $2.852^{*}$ & 0.240 & NS \\
\cline { 3 - 6 } Blood & Staph-aureus & $1(3.3 \%)$ & $1(4.0 \%)$ & $1(6.7 \%)$ & $0.279^{*}$ & 0.870 & NS \\
Culture & Strepto penumonia & $1(3.3 \%)$ & $1(4.0 \%)$ & $0(0.0 \%)$ & $0.583^{*}$ & 0.747 & NS \\
& Pseudomons & $2(6.7 \%)$ & $0(0.0 \%)$ & $0(0.0 \%)$ & $2.745^{*}$ & 0.253 & NS \\
& Acintobacter & $0(0.0 \%)$ & $1(4.0 \%)$ & $1(6.7 \%)$ & $1.784^{*}$ & 0.410 & NS \\
& Acintobacter & $1(3.3 \%)$ & $0(0.0 \%)$ & $0(0.0 \%)$ & $1.353^{*}$ & 0.508 & NS \\
& Citro bacter & $1(3.3 \%)$ & $0(0.0 \%)$ & $0(0.0 \%)$ & $1.353^{*}$ & 0.508 & NS \\
& Candida & $0(0.0 \%)$ & $1(4.0 \%)$ & $0(0.0 \%)$ & $1.826^{*}$ & 0.401 & NS \\
\hline On admission & N.g & $30(100.0 \%)$ & $25(100.0 \%)$ & $15(100.0 \%)$ & - & - & - \\
\hline
\end{tabular}




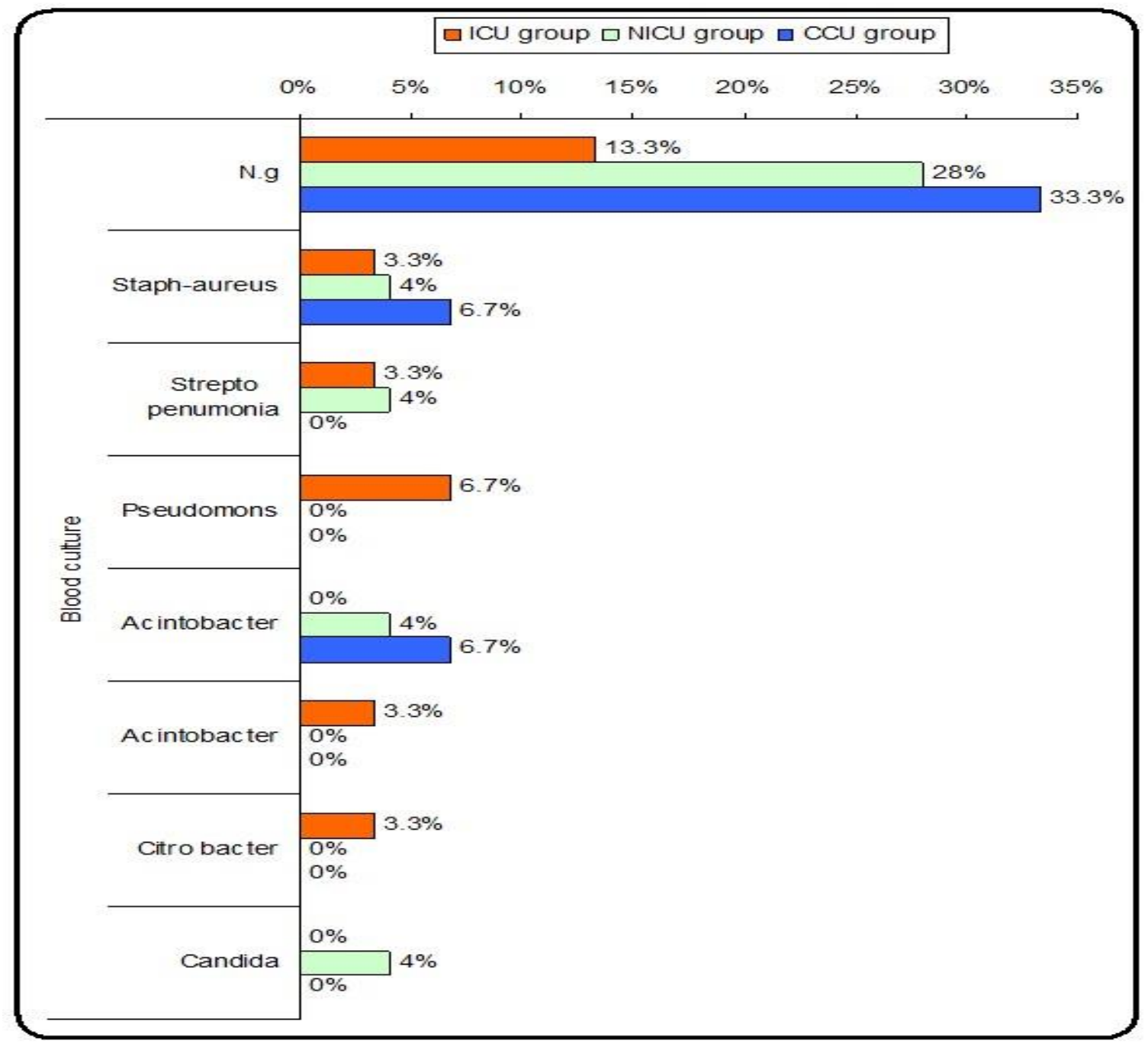

Fig. (3): Distributional of bacterial and fungal presence in the blood cultures' samples among 3 groups of ICU, NICU and $\mathrm{CCU}$

In correlating the results of the air samples with the blood cultures and ETT samples, the ICU group showed $21(70 \%)$ positive air samples to $8(26.6 \%)$ positive ETT samples and $6(20 \%)$ positive blood cultures. the most significant common organism between the air and the ETT fluid is candida. ( $p$ value= 0.021) as shown in table (4).

Table (4): Correlation of the presence of each organism between air samples, ETT samples and blood cultures in the ICU group

\begin{tabular}{|l|c|c|c|c|c|c|}
\hline \multirow{2}{*}{} & \multicolumn{3}{|c|}{ ICU group } & \multirow{2}{*}{ Test value } & \multirow{2}{*}{ P-value } & \multirow{2}{*}{ Sig. } \\
\cline { 2 - 7 } & Organism In air & ETT & Blood Culture & & & \\
\hline Staph. haemolyticus & $2(6.7 \%)$ & $0(0.0 \%)$ & $1(3.3 \%)$ & 2.069 & 0.355 & NS \\
\hline Staph.phermicularis & $0(0.0 \%)$ & $0(0.0 \%)$ & $0(0.0 \%)$ & - & - & - \\
\hline strept.pneumonia & $1(3.3 \%)$ & $0(0.0 \%)$ & $1(3.3 \%)$ & 1.544 & 0.462 & NS \\
\hline Staph.scuri. & $2(6.7 \%)$ & $1(3.3 \%)$ & $0(0.0 \%)$ & 2.069 & 0.355 & NS \\
\hline Staph.aureus & $2(6.7 \%)$ & $0(0.0 \%)$ & $1(3.3 \%)$ & 2.069 & 0.355 & NS \\
\hline Koc.rhizophila & $3(10.0 \%)$ & $2(6.7 \%)$ & $1(3.3 \%)$ & 1.071 & 0.585 & NS \\
\hline Pseudomonas.aeruginosa & $4(13.3 \%)$ & $2(6.7 \%)$ & $1(3.3 \%)$ & 2.169 & 0.338 & NS \\
\hline Acintobacter & $1(3.3 \%)$ & $0(0.0 \%)$ & $0(0.0 \%)$ & 2.022 & 0.364 & NS \\
\hline Citrobacter & $3(10.0 \%)$ & $1(3.3 \%)$ & $1(3.3 \%)$ & 1.694 & 0.429 & NS \\
\hline Candida & $6(20.0 \%)$ & $2(6.7 \%)$ & $0(0.0 \%)$ & 7.683 & 0.021 & S \\
\hline
\end{tabular}

While in the NICU group, the results showed 27 positive air samples where in some samples more than one organism was found in correlation to $8(32 \%)$ positive ETT samples and $8(32 \%)$ positive blood culture. Staph pneumonie was found to be the most common organism between the air samples, ETT samples and blood cultures. The distribution of organisms is shown in table (5). 
https://ejhm.journals.ekb.eg/

Table (5): Correlation of the presence of each organism between the air samples, ETT samples and blood cultures in the NICU group

\begin{tabular}{|c|c|c|c|c|c|c|}
\hline & \multicolumn{3}{|c|}{ NICU group } & \multirow{2}{*}{ Test value } & \multirow{2}{*}{$\begin{array}{l}P \text { - } \\
\text { value }\end{array}$} & \multirow{2}{*}{ Sig. } \\
\hline & Organism In air & ETT & Blood Culture & & & \\
\hline Staph. haemolyticus & $4(16.0 \%)$ & $1(4.0 \%)$ & $1(4.0 \%)$ & 3.261 & 0.196 & NS \\
\hline Staph.phermicularis & $1(4.0 \%)$ & $0(0.0 \%)$ & $0(0.0 \%)$ & 2.027 & 0.363 & NS \\
\hline strept.pneumonia & $4(16.0 \%)$ & $\begin{array}{l}3 \\
(12.0 \%) \\
\end{array}$ & $3(12.0 \%)$ & 0.231 & 0.891 & NS \\
\hline Staph.scuri. & $4(16.0 \%)$ & $0(0.0 \%)$ & $0(0.0 \%)$ & 8.451 & 0.015 & $\mathrm{~S}$ \\
\hline Staph.aureus & $2(8.0 \%)$ & $0(0.0 \%)$ & $0(0.0 \%)$ & 4.110 & 0.128 & NS \\
\hline Koc.rhizophila & $0(0.0 \%)$ & $0(0.0 \%)$ & $0(0.0 \%)$ & - & - & - \\
\hline Pseudomonas.aeruginosa & $2(8.0 \%)$ & $2(8.0 \%)$ & $2(8.0 \%)$ & 0.000 & 1.000 & NS \\
\hline Acintobacter & $1(4.0 \%)$ & $0(0.0 \%)$ & $0(0.0 \%)$ & 2.027 & 0.363 & NS \\
\hline Citrobacter & $2(8.0 \%)$ & $0(0.0 \%)$ & $0(0.0 \%)$ & 4.110 & 0.128 & NS \\
\hline Candida & $7(28.0 \%)$ & $2(8.0 \%)$ & $2(8.0 \%)$ & 5.327 & 0.070 & NS \\
\hline
\end{tabular}

In the CCU group, we had $11(73.3 \%)$ positive air samples in comparison with 5 (33.3\%) positive ETT samples and $5(33.3 \%)$ positive blood cultures as shown in table (6).

Table (6): Correlation of the presence of each organism between the air samples, ETT samples and blood cultures in CCU group

\begin{tabular}{|c|c|c|c|c|c|c|}
\hline & \multicolumn{3}{|c|}{ CCU group } & \multirow{2}{*}{ Test value } & \multirow{2}{*}{$\begin{array}{l}P \text { - } \\
\text { value }\end{array}$} & \multirow{2}{*}{ Sig. } \\
\hline & Organism In air & ETT & Blood Culture & & & \\
\hline Staph. haemolyticus & $1(6.7 \%)$ & $1(6.7 \%)$ & $1(6.7 \%)$ & 0.000 & 1.000 & NS \\
\hline Staph.phermicularis & $1(6.7 \%)$ & $0(0.0 \%)$ & $0(0.0 \%)$ & 2.045 & 0.360 & NS \\
\hline strept.pneumonia & $1(6.7 \%)$ & $1(6.7 \%)$ & $1(6.7 \%)$ & 0.000 & 1.000 & NS \\
\hline Staph.scuri. & $1(6.7 \%)$ & $0(0.0 \%)$ & $0(0.0 \%)$ & 2.045 & 0.360 & NS \\
\hline Staph.aureus & $2(13.3 \%)$ & $0(0.0 \%)$ & $0(0.0 \%)$ & 4.186 & 0.123 & NS \\
\hline Koc.rhizophila & $2(13.3 \%)$ & $1(6.7 \%)$ & $1(6.7 \%)$ & 0.549 & 0.760 & NS \\
\hline Pseudomonas.aeruginosa & $1(6.7 \%)$ & $1(6.7 \%)$ & $1(6.7 \%)$ & 0.000 & 1.000 & NS \\
\hline Acintobacter & $0(0.0 \%)$ & $0(0.0 \%)$ & $0(0.0 \%)$ & - & - & - \\
\hline Citrobacter & $1(6.7 \%)$ & $1(6.7 \%)$ & $1(6.7 \%)$ & 0.000 & 1.000 & NS \\
\hline Candida & $1(6.7 \%)$ & $0(0.0 \%)$ & $0(0.0 \%)$ & 2.045 & 0.360 & NS \\
\hline
\end{tabular}

Collectively, we had $59(84.2 \%)$ positive air samples in comparison to 21 (30\%) positive ETT fluid culture and $19(27.1 \%)$ positive blood cultures in the completely selected air sampling areas and in the selected patients during the included sampling period. 


\section{DISCUSSION}

Regarding that indoor air quality is a crucial factor in maintaining the optimal infection control in different inpatient sectors of health care facilities, it was critical to monitor the indoor air quality. In our study we had a strong relation between the contamination of the indoor air, either by bacterial or fungal organisms, and the concomitant presence of the same organism in the ETT fluid samples and to lesser extent in the blood cultures where $59(84.2 \%)$ positive air samples correlated to $21(30 \%)$ positive ETT fluid culture and 19 (27.1\%) positive blood cultures.

When we compared the results of the selected inpatients sectors, the relation was stronger in the NICU group where 27 of the air samples in the NICU group were positive for bacterial and fungal contamination with $32 \%$ of each of the ETT samples and blood cultures positive. Since the NICU is more subjected to outdoors contacts, by parents or for maternity purposes, which increase indoor air susceptibility for contamination from the outdoor particles or organisms. This supports the relation between air quality and concomitant infections of the patients. The relation between the indoor and outdoor air contamination was proved by a study performed in Iran comparing the concentration of indoor and outdoor air particles and donated the importance of air clearance and this supports our study ${ }^{(6)}$.

The second noticed factor that influenced the results is the site of air sampling inside the unit where it was found that samples obtained from the front of the bed $(28.5 \%$ of the total obtained samples, but $66.7 \%$ of ICU samples with $p$ value $=0$ ) and from the incubator (17\% of the total samples and $48.8 \%$ of NICU samples with $\mathrm{p}$ value $=0$ ) were significant in detecting air contamination, which supports the theory that particular sites are more affected by air contamination. This importance of the site is supported by a study performed in Taiwan in 2015 where a significant difference was found in bacterial concentration in different sites where highest concentration was found in rooms at the front end of the circulation. Thus we could conclude the most beneficial sites where air filter should be located and sites to be more taken care of to minimize susceptibility of patient infection ${ }^{(7)}$.

The third noticed relation is the more probability of ETT samples to be contaminated than the blood cultures, which also supports the relation between air contamination and concomitant patient infection. This is assumed mostly due to the direct contact between the air and the patient's respiratory tract.

\section{CONCLUSION}

The Indoor air quality in health care facilities is highly critical in minimizing the concomitant nosocomial infection. We could achieve an optimal level of indoor air quality by applying the infection control rules, application of approved air filters and strict adherence to hand hygiene. Furthermore, the position of the patient in the healthcare facility is important in achieving the optimal level of patient' protection from air acquired infection by keeping them away from the front of the circulation, sinks and sites frequently subjected to outdoors contact whether from healthcare workers or visitors. Care of the endotracheal tubes and other invasive respiratory support devices is crucial to minimize air-acquired infections.

\section{LIST OF ABBREVIATION}

CCU Cardiac care unit

EEA European Environmental Agency

ETT Endotracheal tube

ICU Intensive care unit

NICU Neonatal intensive care unit

WHO World Health Organization

GOTHIGeneral Organization For Teaching Hospitals and Institutes

\section{REFERENCES}

1. Settimo G, D'Alessandro D (2014): European community guidelines and standards in indoor air quality: what proposals for Italy. Epidemiologia e prevenzione, 38 (6): 36-41.

2. Stefano C, Gaetano S, Marco G (2017): Indoor Air Quality in Healthcare Facilities. Springer, Cham, Pp: 132. https://link.springer.com/book/10.1007\%2F978-3319-49160-8

3. D'Alessandro A, Paglia G, Rolfsson Ó et al. (2016): Biomarkers defining the metabolic age of red blood cells during cold storage. Blood, the Journal of the American Society of Hematology, 128 (13): 43-50.

4. Montagna M, Lovero G, Coretti $\mathrm{C}$ et al. (2014): SIMIFF study: Italian fungal registry of mold infections in hematological and non-hematological patients. Infection, 42 (1): 141-51.

5. Verde S, Almeida S, Matos $J$ et al. (2015): Microbiological assessment of indoor air quality at different hospital sites. Research in Microbiology, 166 (7): 557-63.

6. Mohammadyan M, Keyvani S, Bahrami A et al. (2019): Assessment of indoor air pollution exposure in urban hospital microenvironments. Air Quality, Atmosphere \& Health, 12 (2): 151-9.

7. Chang C, Tseng L, Yang L (2015): Microbial air contamination in an intensive care unit. International Journal of Public Health Science, 4 (3): 145-51. 